\title{
Safety and Efficacy of Oral Mifepristone in Pre-induction Cervical Ripening and Induction of Labour in Prolonged Pregnancy
}

\author{
Yelikar Kanan • Deshpande Sonali • \\ Deshpande Rinku $\cdot$ Lone Dipak
}

Received: 17 April 2014/Accepted: 16 June 2014/Published online: 11 July 2014

(C) Federation of Obstetric \& Gynecological Societies of India 2014

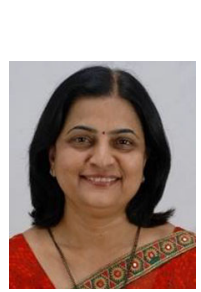

\begin{abstract}
About the Author
Kanan Yelikar is the vice president of FOGSI. She was the chairperson of the Clinical Research Committee (2004-2008). She has more than 50 publications in indexed journals. She has been the Editor of books for more than 20 chapters of the text book, "Practical cases in OBGYn and Essential of Research methodology". She was elected as the "Senate Member" of the Maharashtra University of Health Sciences, Nashik (2003). She was the Chairman Board of Studies Post Graduate, Medicine Faculty, Maharashtra University of Health Sciences, Nashik (2007); Member of Standing Committee, MUHS UG \& PG examiner at various universities in and outside Maharashtra. She has organized many workshops, symposiums, and postgraduate training programmes at Aurangabad. She has also organised more than 50 programmed labour workshops. She is working on prostaglandin and it uses in induction of labour and abortion since 1994 and has published original article on the
\end{abstract} use of misoprostol in medical abortion and induction of labour in the Journal of Obstetrics and Gynecology of India.

\begin{abstract}
Objective(S) To study the safety and efficacy of oral mifepristone in pre-induction cervical ripening and induction of labour in prolonged pregnancy.

$\operatorname{Method}(S) \quad$ This is a single blind randomized control trial. 100 women with prolonged pregnancy beyond 40 weeks and Bishop score $<6$ were recruited, and randomly allocated into two groups. Women who received Tab. Mifepristone $200 \mathrm{mg}$ orally were assigned in Study Group
\end{abstract}

Yelikar K., Professor \& HOD · Deshpande S., Associate Professor . Deshpande R., Assistant Professor · Lone D., Assistant Professor Department of Obstetrics and Gynecology, Government Medical College \& Hospital, Aurangabad, India

Yelikar K. $(\bowtie)$, Professor \& HOD

Ashwini Hospital, 12, Samarth Nagar, Aurangabad 4310051,

Maharashtra, India

e-mail: drkanany@yahoo.co.in $(n=50)$ and who received placebo orally were assigned in Control Group $(n=50)$ At the end of $24 \mathrm{~h}$, change in the Bishop's score was assessed and Tab. Misoprostol $25 \mu \mathrm{g}$ was administered intravaginally every $4 \mathrm{~h}$, maximum 6 doses for induction/augmentation of labour. Analysis regarding safety and efficacy of the drug was done with regards to maternal and perinatal outcome.

$\operatorname{Result}(S) \quad$ Among 100 subjects, 50 received mifepristone and 50 received placebo. Mean induction to delivery interval was $1,907 \pm 368.4 \mathrm{~min}$ for Study Group versus $2,079 \pm 231.6 \mathrm{~min}$ for Control Group. The improvement in mean Bishop score was $5.0408 \pm 1.90$ for Study Group compared with $3.26 \pm 1.15$ was for Control Group after $24 \mathrm{~h}$. Mean dose of misoprostol in Study Group was $40 \pm 27.2$, while the same in Control Group was $52 \pm 19.46$. Eight $(16 \%)$ women in Study Group and two (4\%) women in Control Group delivered vaginally within $24 \mathrm{~h}$ without any need of augmentation. There were 6 (12\%) cesareans and $2(4 \%)$ instrumental deliveries in 
Study Group and $8(16 \%)$ cesareans and 5 (10\%) instrumental deliveries in the Control Group. There was no statistically significant difference in perinatal outcomes between two groups.

Conclusion(S) Mifepristone had a modest effect on cervical ripening when given $24 \mathrm{~h}$ prior to labour induction and appearing to reduce need for misoprostol compared with placebo.

Keywords Mifepristone - Misoprostol · Induction of labour

\section{Introduction}

One of the most common indications for labour induction is prolonged pregnancy as it is associated with the increased risk to the fetus, including increased perinatal mortality rate, low 5-min Apgar scores, dysmaturity syndrome, and increased risk of death within the first year of life. A ripe or favorable cervix is a prerequisite for successful vaginal birth. So, cervical ripening should be assessed before any regimen is selected. Mifepristone is a steroidal compound that has antiglucocorticoid and antiprogesterone properties. It increases uterine activity and causes cervical effacement and dilatation for pregnancy termination. The pharmacokinetics of mifepristone is characterized by rapid absorption and a long half life of 25-30 h [1]. Mifepristone now has an established role in termination of pregnancy during the early first, and the second trimesters [2]. Animal studies have suggested that mifepristone may also have a role in inducing labor in late pregnancy. Hapangama and Neilson [3] in Cochrane collaboration published in 2009 are of the opinion that there is insufficient information available from clinical trials to support the use of mifepristone to induce labor. Keeping this in mind, the present study was undertaken to find out the safety and efficacy of mifepristone for pre-induction cervical ripening and labor induction in women with prolonged pregnancy.

\section{Materials and Methods}

- Design Single Blind Randomized controlled clinical trial

- Number of women 100

- Duration of study June 2012-November 2013

- Inclusion Criteria Women with prolonged pregnancy with maternal age $>18$ years, singleton gestation, cephalic presentation, reactive FHR pattern in live fetus, intact membranes, and bishop's score $<6$.
- Exclusion criteria Estimated fetal weight $>4,500$ or $<2,000 \mathrm{~g}$, antepartum hemorrhages, previous cesarean section, chorioamnionitis, parity $>4$, any medical complications

- Investigation CBC, urine, blood group, USG, NST

- The study was approved by the ethical committee, Government Medical College, Aurangabad. A total 100 identical envelopes were prepared using computergenerated random number table. Study participant did not know about the randomization and group assignment. Each envelope contained mifepristone or placebo. The placebo tablet had been obtained from our college pharmacy and was identical in appearance and texture to the tablet of mifepristone. After detailed history, examination, confirmation of diagnosis, investigations and after written informed consent, women were allocated into two groups. The participant who received Tab. mifepristone $200 \mathrm{mg}$ was assigned in Study Group $(n=50)$ and who received placebo were assigned in Control Group $(n=50)$. In all women, at the end of $24 \mathrm{~h}$, Bishop's score was assessed and if it was $<6$ than Tab. misoprostol $25 \mu \mathrm{g}$ was administered vaginally every $4 \mathrm{~h}$, (maximum 6 doses $-150 \mu \mathrm{g}$ ) till the Bishop score became $\geq 6$ or the women entered in active labor. When the women entered in active labor, ARM was done and if required Oxytocin drip was started for augmentation of labor, but not earlier than $4 \mathrm{~h}$ after the last dose of misoprostol. If fetal heart rate pattern remained normal with satisfactory progress of labor, these women were kept for vaginal delivery. If progress was unsatisfactory or variable fetal heart pattern, these women underwent cesarean section. The efficacy of mifepristone was assessed on the basis of improvement in Bishop score, mean dose of misoprostol required, and duration of induction to active phase of labor.

- The safety of the regimen (mifepristone + misoprostol) was assessed on the basis of adverse effects and maternal and perinatal complications.

- Successful induction was defined as women who entered active labor within $24 \mathrm{~h}$ of administration of mifepristone and misoprostol OR placebo and misoprostol.

- Failed induction was defined as women who failed to enter active labor at the end of $24 \mathrm{~h}$ of administration of mifepristone and maximum dose of misoprostol or placebo and maximum dose of misoprostol.

- For hyperstimulation syndrome, terbutaline $250 \mu \mathrm{g}$ subcutaneous injection was given. Analysis regarding maternal \& perinatal outcome was done.

- Data analysis In the present study, continuous variables were presented as mean with standard deviation. Differences in continuous variables were analyzed with 
test of significance of difference between two means. The difference in proportion was tested with Chi-square test. The demarcating level of statistical significance was found at the probability level of 0.05 .

\section{Results}

Table 1 shows both the groups were comparable regarding maternal age, parity, BMI, and gestational age.

Table 2 shows maternal outcome. At the end of $24 \mathrm{~h}$, there was a significant improvement in mean Bishop's score in Study Group (5.04082 \pm 1.90$)$ compared with Control Group (3.26 \pm 1.15$)$. Mean induction to active phase interval was 1,598 $\pm 346 \mathrm{~min}$ in Study Group compared with $1,763 \pm 210 \mathrm{~min}$ in Control Group which was found to be statistically significant. Eight women (16\%) in Study Group compared with two women (4\%) in control delivered within $24 \mathrm{~h}$ without any need of use of vaginal misoprostol. This was found to be statistically significant. Six women $(12 \%)$ in Study Group and eight women (16\%) in Control
Group underwent cesarean section. Mean induction delivery interval was 1,907 \pm 368.4 min in Study Group compared with $2,079 \pm 231.6 \mathrm{~min}$ in Control Group. This was also found to be statistically significant. Induction of labor was successful in $94 \%$ women in Study Group versus $96 \%$ in Control Group. This was not found to be statistically significant.

Table 3 shows the efficacy and safety of the drug regimen. Mean dose requirement of misoprostol in Study Group was $40 \pm 27.2 \mathrm{mcg}$ compared with $52 \pm 19.46 \mathrm{mcg}$ in Control Group. This was found to be statistically significant. Adverse effects were noted in both the groups and were comparable.

Table 4 perinatal outcome was assessed and comparison was made between healthy baby and Babies with adverse outcome (perinatal death + NICU admission) in the Study Group and Control Group, it was not found to be significant. In Study Group, out of four babies who were admitted to NICU for Apgar $<7$ at $5 \mathrm{~min}$, three babies survived and one baby died on 7th day due to meconium aspiration syndrome. In Control Group, two babies were admitted in NICU for thick meconeum and discharged successfully

Table 1 Characteristics of the study subjects

\begin{tabular}{lccc}
\hline Characteristics & Study Group $(n=50)$ & Control Group $(n=50)$ & Statistical analysis \\
\hline Mean age (years) & $22.98 \pm 3.006$ & $23 \pm 2.893$ & $p=0.89^{*}$ \\
Mean parity & $1.48 \pm 0.64$ & $1.62 \pm 0.44$ & $p=0.659^{*}$ \\
Mean BMI & $20.08 \pm 1.56$ & $21.03 \pm 0.86$ & $p=0.768^{*}$ \\
Mean gestational age (weeks) & $41.15 \pm 0.68$ & $41.18 \pm 0.68$ & $p=0.82^{*}$ \\
\hline
\end{tabular}

* Unpaired ' $t$ ' test

Table 2 Maternal outcome

\begin{tabular}{|c|c|c|c|c|}
\hline S. no. & Variable & Study Group $(n=50)$ & Control Group $(n=50)$ & Statistical analysis \\
\hline 1. & Mean Bishop's Score at $0 \mathrm{~h}($ mean $\pm \mathrm{SD})$ & $2.02 \pm 0.749$ & $2.16 \pm 0.77$ & $\mathrm{p}=0.35^{*}$ \\
\hline 1. & Mean Bishop's score at the end of $24 \mathrm{~h}$ (mean $\pm \mathrm{SD}$ ) & $5.0408 \pm 1.90$ & $3.26 \pm 1.15$ & $\mathrm{p}=0.001^{*}$ \\
\hline 2. & Mean induction to active stage interval(min) (mean \pm SD) & $1,598 \pm 346(\sim 26.63 \mathrm{~h})$ & $1,763 \pm 210(\sim 29.38 \mathrm{~h})$ & $p=0.004^{*}$ \\
\hline \multirow[t]{5}{*}{3.} & Mode of delivery & & & \\
\hline & Vaginal delivery within $24 \mathrm{~h}$ & $8(16 \%)$ & $2(4 \%)$ & $p=0.05^{\#}$ \\
\hline & Vaginal delivery between 24 and $48 \mathrm{~h}$ & $34(68 \%)$ & $35(70 \%)$ & $p=0.74^{\#}$ \\
\hline & Instrumental & $2(4 \%)$ & $5(10 \%)$ & $p=0.43^{\#}$ \\
\hline & LSCS & $6(12 \%)$ & $8(16 \%)$ & $p=0.62^{\#}$ \\
\hline 4 & Mean induction delivery interval (mins) (mean \pm SD) & $1,907 \pm 368.4(\sim 31 \mathrm{~h})$ & $2,079 \pm 231.6(\sim 35 \mathrm{~h})$ & $p=0.0062 *$ \\
\hline \multirow[t]{3}{*}{5} & Outcome & & & \\
\hline & Success & $47(94 \%)$ & $48(96 \%)$ & $p=0.68^{\#}$ \\
\hline & Failure & $3(6 \%)$ & $2(4 \%)$ & \\
\hline
\end{tabular}

\footnotetext{
* Unpaired ' $t$ ' test
}

\# Chi square test 
Table3 Efficacy and safety of drug regimen

\begin{tabular}{|c|c|c|c|c|}
\hline S. no. & Variable & $\begin{array}{l}\text { Study Group } \\
(n=50)\end{array}$ & $\begin{array}{l}\text { Control Group } \\
(n=50)\end{array}$ & Statistical analysis \\
\hline 1. & $\begin{array}{l}\text { Mean dose of misoprostol } \\
\text { required (in } \mu \mathrm{g})(\text { mean } \pm \mathrm{SD})\end{array}$ & $40 \pm 27.2$ & $52 \pm 19.46$ & $p=0.01 *$ \\
\hline \multirow[t]{5}{*}{2.} & Adverse effect & & & \\
\hline & Tachysystole & 1 & 2 & \multirow[t]{4}{*}{$p=0.47^{\#}$} \\
\hline & Hypersystole & - & 2 & \\
\hline & Hyperstimulation syndrome & 2 & 2 & \\
\hline & Stained liquor & 6 & 8 & \\
\hline
\end{tabular}

* Unpaired ' $t$ ' test

\# Chi square test

Table 4 Perinatal outcome

\begin{tabular}{llcll}
\hline S. no. & Variable & $\begin{array}{l}\text { Study Group } \\
(n=50)\end{array}$ & $\begin{array}{l}\text { Control Group } \\
(n=50)\end{array}$ & $\begin{array}{l}\text { Statistical } \\
\text { analysis }\end{array}$ \\
\hline 1. & Perinatal death & 1 & 0 & $p>0.05^{\#}$ \\
2. & Healthy baby & 46 & 48 & \\
3. & NICU admission & 4 & 2 & \\
\hline
\end{tabular}

\# Chi-square test

\section{Discussion}

Research continues to invent and modify doses of different drugs for induction of labor. The female sex hormone, progesterone stops the uterus contracting during pregnancy. Drugs such as mifepristone have been used to stop the action of this hormone, either to induce labor or to allow the pregnancy to be terminated.

In the present study, we opted for $200 \mathrm{mg}$ mifepristone as the tablet is available and the women will get the exact dose without fail. Byrne [4] demonstrated that mifepristone exposure and induced labor were associated with increase in cortisol levels and significant elevation in cortisol levels was observed within $18 \mathrm{~h}$ of exposure to mifepristone. Hapangama and Neilson [3] reported that there is insufficient evidence to support a particular dose, but a single dose of $200 \mathrm{mg}$ mifepristone appears to be the lowest effective dose for cervical ripening(increased like hood of cervical ripening at $72 \mathrm{~h}$ (RR 2.13, $95 \% \mathrm{CI}$ 1.15-3.97).

In our study statistically significant improvement was observed in mean Bishop's score in Study Group at the end of $24 \mathrm{~h}$. This improvement in score indirectly indicates the withdrawal of progesterone support. Wing et al. [5] demonstrated more women had favorable Bishop score after $24 \mathrm{~h}$ of mifepristone than placebo though the difference was not found to be statistically significant. Atawale et al.
[6] and Fathima et al. [7] also noted the significant change in Bishop score with the use of oral mifepristone.

We found statistically significant decrease in the requirement of misoprostol with prior use of mifepristone. Our results were consistent with the literature that shows decreased prostaglandin requirements when mifepristone is given either for second trimester pregnancy termination or term induction. Wing et al. [5] also reported the reduced need of prostaglandin/oxytocin need in mifepristone group.

Frydmann et al. [8] also reported $3 \%$ women went into labor within $24 \mathrm{~h}$ of ingestion of mifepristone. Hapangama and Neilson [3] reported that mifepristone-treated women were more likely to be in labor or to have a favorable cervix at $48 \mathrm{~h}$ (risk ratio (RR) $2.41,95 \%$ confidence interval(CI) 1.70-3.42), and this effect persists at $96 \mathrm{~h}$ (RR $3.40,95 \%$ CI 1.96-5.92). In the present study, eight women $(16 \%)$ in Study Group went in labor and delivered vaginally without any need of misoprostol within $24 \mathrm{~h}$ of ingestion of mifepristone. This was found to be statistically significant and may be co-related that women with prolonged pregnancy may have more chances to go in labor earlier.

In the present study, thirty-four (68\%) women in study delivered vaginally between 24 and $48 \mathrm{~h}$. Similar results were reported by Wing et al. [5]. In the present study, there were $6(12 \%)$ cesareans and $2(4 \%)$ instrumental deliveries in Study Group. Fortunately, we have encountered a single case of PPH that too in misoprostol group which was effectively controlled by administration of therapeutic dose of misoprostol along with uterine massage. There were no major complications in study conducted by Athawale et al. [6]. More spontaneous vaginal deliveries and less incidence of LSCS and less instrumental deliveries were noted by Fathima et al. [7]. Hapangama and Neilson [3] reported that mifepristone-treated women were less likely to undergo cesarean section as a result of failure to induce labor (RR 1.43, $95 \%$ CI 0.20-0, 80) and they were less likely to need the augmentation with oxytocin (RR 0.80, 
$95 \%$ CI 0.66-0.97). The rate of successful induction in our study was $94 \%$ comparable with Wing et al. [5]. Hapangama and Neilson [3] reported abnormal fetal heart rate pattern, common after mifepristone treatment (RR 1.85, $95 \%$ CI 1.17-2.93),but there was no difference in other neonatal outcome. Similar findings were observed in our study.

\section{Conclusion}

Mifepristone is an effective inductive agent for cervical ripening and initiation of labor when given $24 \mathrm{~h}$ prior in prolonged pregnancy with reduced need for prostaglandins and can be administered safely with no increase in adverse events on the fetus or mother.

Ethical statement This study was approved by institutional ethical committee Informed consent was obtained from all the women, before including in the study.

Conflict of interest Dr. Yelikar Kanan, Dr. Deshpande Sonali, Dr. Deshpande Rinku, Dr. Lone Deepak declare that they have no conflict of interest.

\section{References}

1. Heikinheimo O, Kekkonen R, Lähteenmäki P. The pharmacokinetics of mifepristone in humans reveal insights into differential mechanisms of antiprogestin action. Contraception. 2003;68(6): 421-6.

2. Gemzell-Danielsson K. a Sujata Lalitkumar. Second trimester medical abortion with mifepristone-misoprostol and misoprostol alone: a review of methods and management reproductive health matters. 2008;16(31 Supplement):162-1726.

3. Dharani H, James PN. Mifepristone for induction of labour (review). Chochrane Database Syst Rev. 2009; 3, Art. No. CD002865.

4. James D. Byrne, term pregnancy. J Perinatol. 2004;24:416-20.

5. Wing DA, Fassett Michael J, Mishell Daniel R. Mifepristone for preinduction cervical ripening beyond 41 weeks' gestation: a randomized controlled trial. Obstet Gynecol. 2000;96:543-8.

6. Athawale R, Acharya N, Samal S, et al. Effect of mifepristone in cervical ripening for induction of labour. Int $\mathrm{J}$ Reprod Contracept Obstet Gynecol. 2013;2(1):35-8.

7. Fathima S, Nayak SR, Rao B, et al. Mifepristone in induction of labour at term. Int J of Pham Biomed Res. 2013;4(3):164-6.

8. Frydman R, Lelaidier C, Baton-Saint-Mleux C, et al. Labour induction in women at term with mifepristone (RU 486): a doubleblind, randomized, placebo-controlled study. Obstet Gynecol. 1992;80:972-5. 